\title{
CREATIVITY AND INTENTIONALITY: A PHILOSOPHICAL ATTEMPT AT RECONSTRUCTING A CREATIVE PROCESS
}

\author{
Paweł GONDEK (iD* \\ Department of Philosophy of Culture and Rhetoric, Faculty of Philosophy, John Paul II Catholic \\ University of Lublin, Al. Racławickie 14, PL 20-950 Lublin, Poland
}

Received 24 May 2020; accepted 20 January 2021

\begin{abstract}
The paper presents a philosophical proposition of elucidating creativity by means of distinguishing the category of intentionality. The intentional dimension of cognitive content encompasses predispositions for constructing sign systems. Such an intellectual modification of sign systems forms the foundation of dynamic creative acts. However, creative processes are not restricted to the sphere of intellectual operations, but also remain under the influence of object categories. For this reason, the results of creative processes must allow for the potential determinants of sensual matter. A transition between the subjective sphere of possibility and the objective sphere of potency indicates the dynamism of the process. A crucial component of the emergence of intentional relations is formulating the criterion of a creative process. It determines the rules of constructing sign systems, the forms of acceptable transformations as well as the possible modes of allowing for the results of this process.
\end{abstract}

Keywords: creativity criterion, creative process, dynamism, intentionality, potency, sign systems.

\section{Introduction}

A pragmatic approach in creativity studies has resulted in forming numerous conceptions in which the subjective aspect is prevalent. The development of interdisciplinary studies in cognitive science as well as in experimental psychology has extended the knowledge on man's cognitive capacities and the workings of the human psyche. This has enabled more detailed research into the problem of creativity and the methods of improving it. Creativity has ceased to be regarded solely as an artistic act from the domain of art, but it has started to be qualified as each person's capacity. Creativity is perceived now as a personality element constituting one of the essential conditions of man functioning in the world (Tatarkiewicz, 1980, pp. 257-261; Adomaityte et al., 2018). Such a diagnosis seems to be proper, however it has not been fully elucidated yet.

\footnotetext{
${ }^{\star}$ Corresponding author. E-mail: pawel.gondek@kul.pl
} 
The development of creativity studies is manifested by attempts at formulating an adequate definition of creativity. In the methodological context, this condition not only determines the manner of conceiving of creativity but it also delineates its scope with the view to univocally apprehending its inherent elements. Most definitions position the essence of creativity between originality and effectiveness, at the same time emphasizing the value of obtained products. However, a product always constitutes a result of a process. Therefore, an important element of creativity studies is calling attention to its dynamic nature (Corazza, 2016). Highlighting the potency factor in the context of dynamism broadens the research field of the workings of creativity. One also indicates the need for the development of man's creative potential by stressing discovery and seeking new possibilities of accomplishing it (Martin \& Wilson, 2017, pp. 419-423). However, regarding potency as a dynamizing factor requires an explanation of the manner of arriving at acts of creativity on this basis. The condition constituting creative acts are epistemic relations, in which the subject's potency is actualized under the influence of an object of cognition. The participation of object factors in creativity processes is elucidated by means of distinguishing the category of intentionality. It is understood as a mode of mentally grasping the cognized states of things in their sign dimension. Husserl's $(2006,2008)$ understanding of intentionality as a conscious way of presenting object data provided the grounds for the constitution of a qualitative structure of the immanent objectivity (Smith, 1982, pp. 87-152). On the basis of phenomenology, the structuring of intentional acts became a causal factor determining all objectivity. Therefore, intentionality became an indispensable component of research in philosophical epistemology. Intentionality is an expression of the presence of creative factors in the processes of intellectual cognition. However, in the perspective of creative processes, the field of intentional acts extends beyond intellectual cognition and constitutes a constructional moment, conditioned by the potential properties of non-mental reality. Thus, the epistemic aspect of creativity requires a broader, philosophical research context.

The text focuses on the presentation of the creativity process in the context of the factors by virtue of which it can occur. Due to the ambiguous nature of the process and the specific character of the mental factors involved in it, the method of this study has been defined as reconstruction. This approach indicates the crucial role of the category of intentionality in elucidating creativity processes. Deriving inspiration from the studies in the field of the philosophical theory of being, and in particular from the position of the Lublin philosophical school, the author emphasizes the ontic value of intentional acts (Krapiec \& Maryniarczyk, 2010, pp. 23-36, 89-102; Kamiński, 2018; Chudy, 2018). On the basis of the research of the school, and especially in the position of Krąpiec, we find an original proposal of formulating the relationship that holds between the intentional dimension of intellectual acts and the creation of cultural works (1983, pp. 167-184). On this basis, my proposal for understanding creative processes will be formulated in this article, taking into account the participation of potentially conditioned sensual matter. Creativity constitutes the result of a multi-step relationship, which holds between a subjective cognitive sphere and the extramental reality. The results of such a process may have their continuation, should they be expressed in some type of sensual matter. This is not a precondition for creative acts. However, it provides the possibility of verifying the value of creative acts. The suggested solution 
may complement the interdisciplinary studies into creative processes. A philosophical look at the phenomenon of creativity results in the fact that they cease to be hermetic and verifiable only in a specific model.

\section{Epistemic foundations of creative acts}

Man's cognitive orientation, both in the material and formal orders, provides the basis for the occurrence of creative processes. On the one hand, it accumulates cognitive content, forming the intellectual body of knowledge, which enables the emergence of creative acts. On the other hand, what is important is also a formal dimension of cognition enabling the formation of the intellectual construction of thinking processes. However, it does not signify limiting creativity to the epistemic domain. Rather it indicates the presence of cognitive acts in all personal human acts. They play the role of a source providing cognitive content and a factor enabling the transformation of the cognized content. At this juncture, it may be argued that creativity processes are epistemically grounded, since creativity processes require allowing for a cognitive act as an act of reading the structure of reality. An adequate cognitive grasp of reality provides a wide content scope, in which the structural factors of the cognized thing are equally not ignored. It is a sign-producing operation consisting in the intellectual production of the signs of things being cognized. The ensuing intentional moment enables an intellectual transformation of the sign, opening up the possibility of generating creative acts.

The cognition process itself already encompasses a creative moment. It involves a transformation of states of things transcendental in relation to the subject. As a result of this process, they assume the form of non-material modes of grasping content in the awareness of the cognizing agent. Grasping a content is aimed at comprehending what we cognize. It reveals itself in the consciousness of the cognizing agent as the meaning of a thing derived from the content. Cognitive contents in this process are not something independent, but they constitute an epistemic fashion of grasping concrete things. Therefore, contents involve individual data conditioned by the place and time, which do not fall within the scope of the meaning itself. The meaning is formed by deriving what is general and constant from the grasped contents. These functions in consciousness as a notion, i.e., a sign of the thing being cognized. In Krąpiec we find the conception of the cognition process, which emphasizes the specific character of the moment of transition from an extra-mentally existing thing to its conscious grasp in the intellect. It consists in the intellectual creation of a formal representation of the thing. Thereby in cognitive processes, there occurs a transformation of the content of the cognized thing into what constitutes the meaning of this thing in consciousness (Krąpiec, 1983, pp. 152-157). Consequently, the existential moment of a cognized thing is transformed into an intentional moment. A mental grasp of the cognized states of things in their sign dimension assumes the form of intentional sign systems. They constitute subjectively grasped and intellectually ordered cognitive contents, which acquire, to a certain extent, an independent mode of mental functioning. In our research, this conception will provide one of the bases for reconstructing the creative act.

We have pointed out that in formulating cognitive contents there occurs a transformation of the existential moment of the cognized thing. The existential moment determines 
the concreteness of the existence of a thing. We are unable to keep this moment in a cognitive grasp of a thing. The theory of being indicates that it is not possible to construct a sign of the existence of something. Despite the fact that the grasped cognitive content primarily becomes a sign of a particular thing being cognized, its concreteness disappears in the intentional dimension. In cognitive acts, an intellectual modification of the cognitive content takes place. It is grounded in the pursuit for generalizing these contents. At the same time, there occurs a cognitive pursuit for rejecting individual properties of these things, i.e., the ones, which are not necessary to grasp a thing intellectually. This is why, for example, an intellectual grasp of a chair has neither a size nor a color. Thus, this process entails a radical transformation of both the existential moment and the individual properties of a thing (Krapiec, 1990, pp. 192-197). On the one hand, the content is separated from the specific existence of a cognized thing; on the other hand, the content itself is reorganized. An ontic perspective becomes an epistemic perspective, additionally dependent on subjective cognitive determinants. In the cognitive order, this constitutes the primary modifying moment of the cognized object. This leads to obtaining a sign representation of the object as a mental state. Nevertheless, despite this modification, the representation of a cognized object is conditioned by the reality of this object. At this stage, it constitutes merely its sign. The specific character of this stage is determined by the truth-oriented moment at which a system of content adequate to the cognized thing is cognitively forged.

Forming sign representations does not constitute purely creative acts. For the participation of the cognizing subject in this process is conditioned by the content of the thing being cognized, whereas the aim of the process is to recreate the content in its relational system, and not to create a new one. A cognizing subject many times performs cognitive acts in a spontaneous, even natural manner. However, while recreating a content, a subject is incapable of grasping the cognized thing comprehensively, since human cognition is an aspect of cognition not necessarily grasping the very thing substantially in a spontaneous grasp. Therefore, at the level of reflected cognition, a precise sign grasp of the content takes place by means of complementing and ordering the system of relations holding in the cognized thing. This is still not a purely perceptive stage, since at the level of reflected cognition, it is possible to engage in the cognized content of subjective factors coming from the outside of the cognized thing (Kamiński \& Krąpiec, 2020, pp. 20-42). What is meant here are in particular factors coming from the sphere of memory and imagination. For this reason, at a reflected level there may occur acts of forming notions as signs of the cognized thing. Thus, an intentional domain is created for which the criterion of correspondence to the cognized thing remains fundamental.

The intentional moment occurring at the level of reflected cognition displays the potential nature of a cognitive process. It consists in the subject's capacity for constructing a system of sign relations. They do not necessarily have to be conditioned by what is current that is by the existing thing. It is the subject, who decides whether, with respect to the thing being cognized, they will apply the correspondence criterion between the system of signs being constructed and the very thing being cognized. Were there no potency in cognitive acts, there would also be no possibility of modifying the system of sign relations and of formulating the correspondence criterion. In cognitive processes, it is the thing being cognized that 
is the reference point. Whereas the subject, being adequate to the thing, only realizes their cognitive potency. A cognizing subject has an inherent capacity for cognizing things. They also have the possibility of operating a system of sign relations in such a manner that the cognized content may be adequate to the thing being cognized. A manifestation of this correspondence is the classical definition of truth as adaequatio intellectus et rei. The cognitive potency moment of the subject provides the grounds for accomplishing the process adequate to the cognized thing. In the cognitive order, this is the first modification of cognized content. Therefore, its result is termed as primary intentionality in the theory of being.

The subjective intentional sphere is not constrained to purely cognitive acts. Cognition results may undergo modifications by constructing intentional sign relations. They may provide grounds for critical thinking or for formulating thought experiments (Yi, 2018). Thought processes as intellectual operations on signs enable a recreation of a network of relations. They are identical to the relations in the cognized thing itself. However, it is also possible to construct a system of relations, which is not grounded in the cognized things themselves. They are founded on potency states, resulting from potential capacities of signs for creating diverse relation systems. What one deals with then are intellectual sign operations constituting a consequence of mental cognitive processes. The correspondence criterion is substituted in them by a different criterion. Each criterion of operating intellectual sign relations, which is not formulated with regard to correspondence constitutes a creativity criterion. Thus, signs created in relation to the cognized thing provide the grounds for thought processes, which concentrate on speculative or constructive systems of sign relations. The field of the possibility of these operations taking place may occur in the order of content and scope. At the level of primary intentionality, the only factor determining creative acts are logical thinking principles.

A moment of cognitive activity does not take place in man in an isolated manner. Creative acts do not originate solely in the intellectual sphere. They also involve sensual cognitive powers. Within the framework of the epistemic unity of the subject, the functions of sensual and emotional powers are distinguished due to their exceptional importance in creative processes. A particular part is played in this respect by the imaginative sphere, which constitutes a key contributor in relation to the intellectual sphere. At the level of imagination, creative possibilities are visualized by virtue of associating impressions with sensual cognition. Impressions do not refer to the intellectual sphere of notions, but to concrete sensual data. However, they hold a direct relationship with intellectual operations on signs. Nevertheless, in a creative process, impressions not only constitute a graphic realization of intellectual operations. For, it is already as part of impressions that there may occur sensual creative processes, which constitute graphic modifications of sensual data. Impressions, aided by memory, may overlap with other impressions, the relation, of which is grasped by the intellect. Thanks to this, there may occur creative processes consisting in the synthesis of impressionary sensual data. In the intentional order, this also provides grounds for constructing impressionary elements. The ability to handle sensual data in the context of intellectual sign structures constitutes a fundamental function of imagination. For this reason, the role of imagination in creative processes is defined as cognitive manipulation (Stokes, 2014, pp. 171-177). By virtue of imagination, a creative process is concretized based on sensual impressions. It is an important factor connecting creative acts with the domain of the intersubjective appraisal of their value. 
Creative acts are associated with discerning in the cognitive structure of a thing the possibility of its intellectual modification. The accumulated cognitive data constitute the intentional material based on which such thought operations may take place. The principal property of these operations is the capacity for formulating intentional sign constructions. It is from exercising this capacity that all creative processes begin. Whereas formulating the intentional constructions of this process is accomplished by choosing a criterion, we understand it as a method of organizing and processing a system of sign relations. Therefore, creative processes encompass three essential moments of 1) initiating a creative act as the purpose of acting, 2) constructing possible criteria for a system of sign relations for this act and 3) selecting a specific criterion. Each of these elements affects the formation and course of a creative process. The purpose of a creative act is understood as the motives, which initiate the formation of such processes. The moment of the possibility of constructing a content is distinguished by seeking various manners of grasping systems of sign relations, created on the basis of cognitive data, while the freedom of creative acts is expressed by choice. It is conceived of as a possibility of selecting such and not another manner of constructing sign systems. This is how the primary constitution of the creative process takes place. At this stage, it constitutes a combination of intellectual construction factors and decision factors manifested by formulating the criterion of constructing sign systems.

\section{The specific character of intentionality in formulating the creativity criterion}

The methodology of formulating a criterion delineating the workings of a creative process is not constrained to subjective acts of constructing sign systems. The primary form of intentionality emerging from cognitive acts is not a condition sufficient for the complete emergence of personal creative processes. It is also essential to transition from subjectively initiated creative acts to the inter-subjective execution of the constructed sign systems. Discovering the possibilities of employing these constructions constitutes an element of the creative process. The inter-subjective dimension of the value of creative acts may be verified by applying the discovered possibilities or by subjecting them to social assessment. This occurs at the interface between intentionality and extra-psychic material in which a constructed sign system is realized. Such a realization may at the same time play the function of an interpersonal message. The results of its construction have the form of a communication. The form of a communication is assumed by each work of art. Also, other creative actions have some form of social fulfillment in the sphere of intention or performance. This is why formulating the criterion of the creative process requires taking into account the stage of accomplishing the result of the process in the construction phase.

Since creative processes are based on signs, being a derivative of human cognitive processes, the reference point for the criterion cannot be only the sphere of intentional sign systems. For in cognitive acts we refer to transcendental, with regard to the subject, real states of things, deriving cognitive content from them. Thus, states of things are a material source for subjective creative operations. At the same time, real states of things constitute the place of accomplishing externalized results of these operations. Displaying the specific character of the realization of a creative process requires its reconstruction in which generalized 
intellectual sign systems provide the grounds for creating a concrete, really existing thing. This will not be a straightforward transition from subjective content to objective content, because what is general does not involve concretization in itself. This is why concretization requires a concretizing factor, i.e., providing an opportunity for the result of an intellectual construction to be executed. In this situation, the concretizing factor is a type of matter. This does not need to be matter conceived physically, in which a creative idea is executed, like for instance a sculpture in stone. This may be a creative use of body organs, like for example during voice production or making a gesture, since the human body, apart from all its organic functions, also plays a crucial communicative role. At this juncture, one also indicates the use of conventional language signs, playing the function of a formal carrier for the communicated creative acts. Due to the communicative aspect, all forms of executing creative acts in the extra-psychic domain may be defined as sensual matter.

Sensual matter enables a wide range of manners of executing intentional sign constructions. However, each form of matter functions as something shaped by a system of parts, by a shape, or by rules. Sensual matter is not in a state of ontic readiness for intentional possibilities to be executed in it. This is why discerning the manner of executing what is intentional in sensual material must, at the same time, be a discovery of the potency of this material. In the context of creativity studies, one needs to stress the difference between possibility and capability. We have already pointed out the specific character of intentional states, the basis for which is provided by logical principles of thinking. Possibility pertains primarily to the principle of non-contradiction - what is non-contradictory is possible. In the intentional order, it is a sufficient condition for the occurrence of acts of thought. Whereas in the ontic order, we are dealing with established systems of things which involve potency factors determining the acceptability and the scope of transformations in a given system (Krąpiec, 1991, pp. 225-226). This connection of intentional possibility with ontic capability is a manifestation of the degree of complication, which occurs in creative processes. Additionally, there are structural conditions of human action itself. They assume the form of decision acts in which the media of executing intentional constructions are selected. Discerning the interface that holds between the two orders is of essential significance for shaping the criterion of the creation and execution of a creative process.

Like in every human action, also in creative processes there occur causal determinants depicting this process from a causal perspective. The principal cause in the description and elucidation of action is a teleological cause, which constitutes the motive for the undertaken actions. The selection of means to achieve an end, especially in moral action, is largely determined by a motive. Whereas in creative processes, the order of occurrence of causes seems to be a secondary matter, since this process may involve various types of conditions and contexts, which affect its course. Subjective inspirations influencing creative activity cannot be limited to a definite range of means. In this case, what is of value is both the end of action and concentration on the selected means. Often there occurs a situation in which, under the influence of the selected means, the intentional construction of a work is perfected or the end of this action is modified. This complicates the manner in which the structure of creative action is shaped methodologically and obstructs the acquisition of such an ability in educational processes (Beghetto \& Karwowski, 2018, pp. 148-151). This does not mean that 
creativity cannot be used in education. The grounds for methodicalness need to be sought in the sphere of the norms of constructing a product, taking into account the conditions of its emergence. A system of causal factors is accumulated in an adequately expressed criterion of the occurrence of a creative process.

As part of the constructed criterion of a creative process, there occurs a synthesis of the causal factors involved in this process. They have both a subjective and an objective dimension. In the subjective sphere, one selects intentionally constructed sign systems, the basis for which are acts of cognition of real states of things. Whereas in the objective sphere, one returns to real states of things, in which the results of a creative process are expressed. The criterion of a creative process is constituted in the thus forged relational transition. The process is conditioned by three causal criteria: the end of a process, the manner of externalizing an intentional construction and the material by means of which the result of the process is manifested. They delineate what is decisive for creativity - the interface between intentional constructions and the real grounds for their realization, i.e., the material undergoing direct or indirect transformations. This intentional-transformational relation seems to be the pivotal moment for the whole creativity process.

What is crucial for the formulation of the criterion is the dynamism inherent in the manner of executing a creative process. Its construction does not involve constant, univocal elements, but analogously conceived, causatively conditioned transformations. In this regard, what acquires particular significance is the sensual matter thanks to which the intentional construction may be externalized. The possibility of executing an intentional construction is linked in sensual matter with ontic potency and with the realization of its final form (Krąpiec, 1983, pp. 179-182). Thus, an intentional construction is externalized and the material in which it is expressed is molded. The intentionality of the construction extends in the creative process into the potency of the sensual material in which the external causes for its execution are accumulated. Therefore, the criterion must encompass the potential nature of sensual matter and the ontic dynamism of systems of things, in which the intentional construction may be executed. The transition from potency to an act occurring at this stage is a manifestation of the dynamism of the creative process. The potency of the sensual material is overlaid with one of the possible intentional constructions. In the theory of being, this is defined as secondary intentionality.

Thus, the formulation of the criterion of a creative process is accomplished by means of constructing contents intentionally and by recognizing the rules of a possible implementation of this content. Therefore, already at the level of primary intentionality, a pre-requisite for the creative process is adjusting the construction of sign systems to the potency of the systems of things, involved in sensual matter. The rules of potential modification of the extra-psychic material delineate in this process the possible boundaries of the intentional construction of contents. This is not a narrow field, which is best shown by the development of discoveries in the domain of the physical laws of matter and of technical possibilities of modifying matter occurring under the influence of social postulates of scientific-technical advancement. A philosophical elucidation of the phenomenon of the potency of matter refers to the ontic structure of material things. The factor determining its mode of existence is a particular form of thing. The potency of sensual matter is limited by the formal factor, which delineates its 
field of acceptable modifications (Krąpiec, 1991, pp. 350-375; Jaroszynski, 2002, pp. 49-54). Due to the recognition of the form of material things, the criterion of a creative process must encompass its execution in sensual matter. Therefore, the criterion needs to involve a method of an analogous application of intentional sign constructions by modifying the form of sensual matter. The transition to the level of secondary intentionality takes place by means of an appropriately constructed structure, analogous to real states.

The execution of a creative process gains thanks to the secondary intentionality of ontic supplement. At the same time, the possibility of verifying its value opens up. At this stage, the creative process enters the intersubjective field of the execution of intentional sign constructions. At the same time, it gains metaphysical grounds for the formation of the creative process, which is immanent in its essence. The factor ensuring the possibility of an ontic supplementation of this process is the parallelism holding between the cognized content, constituting the basis for sign constructions and the results obtained by means of employing this construction. Such a parallel is feasible thanks to the ambiguous fashion of constructing a sign structure of the content in creative acts. What one strives at in creative processes is not to develop necessary and constant intellectual content but to achieve a structure, which is possible to implement. Therefore, the rules grasped in cognizing and expressing the modes of existence of things become at the same time, the basis for executing creative processes in sensual matter. And in spite of the fact that a creative process is formulated at a level of intellectual sign constructions, it still requires allowing for real object conditions. Thus, a creative act is to a certain extent guided by the ontic rules of the cognitively grasped things, which, at the same time, determine the scope of possibilities for its execution. An intellectual carrier of these rules are sign systems formulated analogously to the cognitively grasped things.

The discernment, by means of analogously grasped semantic systems, of potency in the structure of the cognized things provides the starting point for the execution of creative processes. Thus, the intellectual grasp of the cognized thing is a prerequisite to the creative process. This is the first construction moment of the intellect, which occurs already in the order of primary intentionality. However, it must not be conceived of as a purely intellectual construction, independent from reality. It is an intellectual sign grasp, guided by the cognition of a thing. It is a guarantee of the reality and applicability of the results of a creative process. In creative processes, it is possible to depart significantly from the cognized states of things in terms of their construction. However, after all, it is the recognition of the potency of matter that all its modifications, adjusting it to the construction structure, are based on. Therefore, the formulation of the criterion and its execution does not involve adjusting only to the real states of things, but also to the potential disposition of things. Discerning real potency enables one to construct sign systems in an advanced manner. This moment constitutes the beginning of formulating the criterion of a creative process. This stage involves not only the emergence of the intent of a process, but also the recognition of its end and the manner of its externalization. However, it is only confronting the results of thought construction operations on signs with sensual material that constitutes a verifiable expression of creativity. The extra-mental material processed as a result of this process is the second creative moment, manifesting itself in secondary intentionality. Thus, creativity is a process of an intellectual transition from primary intentionality to secondary intentionality. 


\section{Conclusions}

The presented outline of a philosophical reconstruction of the creative process seeks, in the first place, to point out the factors dynamizing this process. The aim is to clarify the basis for definitions of creativity, which emphasize the significance of dynamism. The understanding of dynamism is grounded in identifying the relation, which holds between subject and object factors in creative processes. This relation is elucidated in terms of intentionality, which enables the relationship between the subjective sphere of intellectual cognitive acts and potential properties of extra-mental reality. In the first place, the focus is on the possibilities of constructing sign systems occurring at an intellectual level. The basis for such thought operations is the intentional dimension of the results of a cognitive grasp of states of things. Thus, intentionality constitutes the category determining the possibilities of modifying sign systems. However, intellectual modification of sign systems takes place in object categories. Creative processes begin from a cognitive grasp of real states of things and conclude in results expressed in extra-mental sensual matter. Therefore, a definition of creativity should encompass the dynamism that holds between a subjective sphere of possibilities in the semantic domain and an objective sphere of potency in the object domain. This is the sphere of forming relations, the motive of whose creation are creative acts, and the moments determining relational relationships are intentional factors. Thus, creativity as an act is positioned between the extra-cognitive possibilities of a subject (primary intentionality) and reading the potency of the extra-mental material (secondary intentionality). The intentional-transformational relation of the two moments constitutes the basis for a creativity process.

In the relational perspective of intentional relations the criterion according to which a creativity process occurs is a crucial element. The factors affecting the formation of the criterion are conditioned by the motive and result of an action, whereas the essence of the criterion are possible manners of externalizing intentional sign constructions. The creativity criterion constitutes the rules of constructing sign systems and specifies the forms of acceptable transformations, which may be obtained as the result of a creative process. The application of the constructed sign systems must allow for the condition of an analogous adaptation to the matter in which the result of this construction is to be manifested. The analogous grasp is pivotal here both for the level of primary and secondary intentionality. In primary intentionality there is no constraint of a creative act to disambiguating notional grasps, which leaves a broad spectrum of possibilities to construct content intellectually, while in secondary intentionality, without an analogous approach it is not possible to recognize the potency of sensual matter, which ultimately determines the results of creative processes. Therefore, the criterion also entails deliberation on modes executing a creative process. The criterion reaches its culmination in selecting the construction of a sign system possible to materialize in sensual matter.

In the context of such propositions, one also needs to point out the social significance of creative acts. From the moment of the conclusion of a creative process, there begins a stage of verifying its results in the intersubjective sphere of interpersonal communication. By means of secondary intentionality, creativity unveils its value, which consists primarily in the correspondence of the product with the criterion formulated by the creator. In this perspective, the appraisal of the value of a product becomes possible. This is enabled by an intersubjective dimension of the product and an ever-increasing knowledge of man's mental 
states and the laws governing them. At the same time, the analysis of a product in the context of the criterion may provide the basis for formulating methods of perfecting creative acts. Perfecting creativity is perfecting the manner of recognizing and interpreting the results, but also perfecting construction forms of sign systems. This requires not only clarifying the rules which will be able to distinguish what is creative, but also determining the criteria of evaluating creativity. This provides the grounds for education in creativity.

\section{References}

Adomaitytè, G., Žilinskaitè, V., Sederevičiūtė-Pačiauskienė, Ž., Valantinaitė, I., \& Navickienė, V. (2018). Shift of creativity concepts: From mysticism to modern approach. Filosofija. Sociologija, 29(3), 203210. https://doi.org/10.6001/fil-soc.v29i3.3777

Beghetto, R. A., \& Karwowski, M. (2018). Educational consequences of creativity: A creative learning perspective. Creativity: Theories - Reaserch - Aplications, 5(2), 146-154. https://doi.org/10.1515/ctra-2018-0011

Chudy, W. (2018). Mieczysław Albert Krąpiec in The Universal Encyclopedia of Philosophy. Studia Gilsoniana, 7(4), 549-566.

Corazza, G. E. (2016). Potential originality and effectiveness: The dynamic definition of creativity. Creativity Research Journal, 28(3), 258-267. https://doi.org/10.1080/10400419.2016.1195627

Husserl, E. (2008). International library of philosophy. Logical investigations, Vol. 1. J. Bermúdez, T. Crane, \& P. Sullivan (Eds.). Routledge.

Husserl, E. (2006). International library of philosophy. Logical investigations, Vol. 2. J. Bermúdez, T. Crane, \& P. Sullivan (Eds.). Routledge.

Jaroszynski, P. (2002). Catholic thought from Lublin. Metaphysics and art. Peter Lang Publishing.

Kamiński, S. (2018). The methodological peculiarity of the theory of being. In S. Kamiński, On the methodology of metaphysics (pp. 205-248). Polskie Towarzystwo Tomasza z Akwinu/Società Internazionale Tommaso d’Aquino.

Kamiński, S., \& Krąpiec, M. A. (2020). The specificity of metaphysical cognition. In S. Kamiński, On the metaphysical cognition (pp. 9-94). Polskie Towarzystwo Tomasza z Akwinu/Società Internazionale Tommaso d'Aquino.

Krąpiec, M. A. (1983). I-Man: An outline of philosophical anthropology. Mariel Publications.

Krąpiec, M. A. (1990). Is linguistics a prerequisite to philosophizing? Angelicum, 67(2), 185-202.

Krąpiec, M. A. (1991). Catholic thought from Lublin. Metaphysics: An outline of the history of being. Peter Lang Publishing.

Krąpiec, M. A., \& Maryniarczyk, A. (2010). The Lublin philosophical school. Polskie Towarzystwo Tomasza z Akwinu.

Martin, L., \& Wilson, N. (2017). Defining creativity with discovery. Creativity Research Journal, 29(4), 417-425. https://doi.org/10.1080/10400419.2017.1376543

Smith, D. W. (Ed.). (1982). Husserl and intentionality: A study of mind, meaning, and language. D. Reidel Publishing Company.

Stokes, D. (2014). The role of imagination in creativity. In E. S. Paul \& S. Barry Kaufman (Eds.). The philosophy of creativity: New essays (pp. 157-184). Oxford University Press. https://doi.org/10.1093/acprof:oso/9780199836963.003.0009

Tatarkiewicz, W. (1980). Melbourne international philosophy series. A history of Six Ideas: An essay in aesthetics, Vol. 5. J. T. J. Srzednicki (Ed.). Martinus Nijhoff Publishers/Polish Scientific Publishers.

Yi, H. (2018). Constitutive and depictive creativities in philosophy and critical thinking. Creativity Studies, 11(1), 24-40. https://doi.org/10.3846/cs.2018.349 